\title{
Descriptive Analysis of Chest Computed Tomography Scan in Coronavirus Disease 2019 Pneumonia: Correlation with Reverse Transcription-polymerase Chain Reaction and Clinical Features
}

\author{
Rusli Muljadi*, Mira Yuniarti ${ }^{1}$, Ricardo Tan $^{2}$, Teodorus Alfons Pratama ${ }^{2}$, Ignatius Bima Prasetya ${ }^{3}$, Allen Widysanto ${ }^{4}$, \\ Gilbert Sterling Octavius ${ }^{2}$ \\ ${ }^{1}$ Department of Radiology, Faculty of Medicine, University of Pelita Harapan, Tangerang, Banten, Indonesia; ${ }^{2}$ Department of \\ Radiology, Faculty of Medicine, University of Pelita Harapan, Tangerang, Banten, Indonesia; ${ }^{3}$ Department of Internal Medicine, \\ Faculty of Medicine, University of Pelita Harapan, Tangerang, Banten, Indonesia; ${ }^{4}$ Department of Respirology, Faculty of \\ Medicine, University of Pelita Harapan, Tangerang, Banten, Indonesia
}

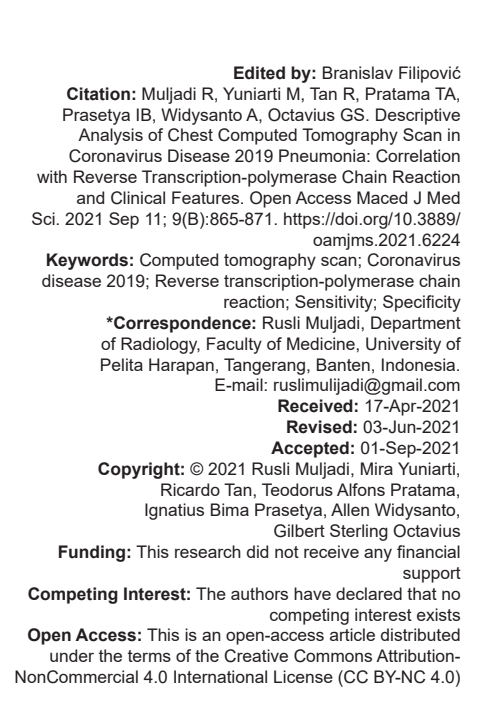

\begin{abstract}
BACKGROUND: Reverse transcriptase-polymerase chain reaction (RT-PCR) is the primary diagnostic tool to confirm coronavirus disease 2019 (COVID-2019) due to its high specificity. However, it has relatively low sensitivity and time consuming. In contrast, chest computed tomography (CT) has high sensitivity and achieves quick results. It may, therefore, play a critical role in screening and diagnosing COVID-19. A cross-sectional study was done in 212 patients with confirmed cases and patients under surveillance for COVID-19 tested for RT-PCR and chest CT scan. Statistical analysis was performed using SPSS Version 23 (Statistical Package for the Social Sciences, IBM Corp., Armonk, NY, USA)

AIM: We aim to investigate the diagnostic value of chest CT in correlation to RT-PCR in Indonesia

METHODS: A cross-sectional study was done in 212 patients with confirmed cases and patients under surveillance for COVID-19 tested for RT-PCR and chest CT scan. Statistical analysis was performed using SPSS Version 23 (Statistical Package for the Social Sciences, IBM Corp., Armonk, NY, USA)

RESULTS: From a total of 212 patients, $92 \%$ of them were diagnosed as confirmed cases of COVID-19. It was found that the sensitivity of CT scan for COVID-19 patients was $72.3 \%(65.5 \%$ and $78.5 \%)$ with positive predictive value (PPV) of $93.9 \%(90.9 \%$ and $96.0 \%)$ and the sensitivity and PPV improve in symptomatic patients. Typical chest CT scan lesions were 8.0 times which were more likely $(3.9-16.4 ; p<0.001)$ to be detected in symptomatic patients while patients with severe CT scan findings were 4.4 times more likely $(3.0-6.5 ; p<0.001)$ to be admitted to the intensive care unit.

CONCLUSION: A high PPV suggests that a chest CT scan can detect COVID-19 lesions, but the absence of the
\end{abstract} lesions would not exclude the disease's presence.

\section{Introduction}

A cluster of pneumonia cases of unknown etiology in Wuhan, China, was reported to the World Health Organization (WHO) in December 2019 [1]. The infectious agent responsible for this outbreak was identified to be a new type of coronavirus, the severe acute respiratory syndrome coronavirus 2 (SARS-CoV-2), and the disease caused by this new virus was officially named coronavirus disease 2019 (COVID-19) [2]. Human-to-human transmission was confirmed shortly after [3], primarily through respiratory droplets [4]. As a result, COVID-19 was able to rapidly spread throughout China and eventually to other countries worldwide. Subsequently, it was declared a pandemic by the WHO in March 2020 [5]. As of July 26, 2020; there have been 15,785,641 confirmed
COVID-19 cases globally, including 640,016 deaths, while Indonesia had 97,286 confirmed cases, including 4714 deaths [6].

Clinical features of COVID-19 can range from asymptomatic or mildly symptomatic to critical illness or even death. Signs and symptoms include fever, respiratory symptoms such as cough and shortness of breath, and non-respiratory symptoms, including anosmia, gastrointestinal and neurological symptoms, and cardiovascular events [7], [8]. Mild-to-moderate illness constitutes about $81 \%$ of cases, while severe and critical illness makes up $14 \%$ and $5 \%$ of cases, respectively [9].

Diagnosis of COVID-19 is confirmed by reverse transcription-polymerase chain reaction (RT-PCR), which amplifies the genetic material of SARS-CoV2 obtained from naso-oropharyngeal samples [10], and is considered the gold standard for COVID-19 detection [4]. 
However, it typically takes hours to complete, and with a sensitivity ranging from $30 \%$ to $90 \%$, it has a high false-negative rate [11]. Chest computed tomography (CT) is the imaging modality of choice in COVID-19 due to its high sensitivity and ability to achieve quick results [10]. Its sensitivity of $98 \%$ is significantly higher than that of the RT-PCR [12]. Furthermore, with 3.9\%, chest CT was found to have a low rate of missed diagnosis of COVID-19 [13]. As a consequence, chest CT enables a quick diagnosis of COVID-19 pneumonia and may play a role in screening for COVID-19, particularly in RT-PCR-negative patients [12], [14], [15].

Typical CT findings of COVID-19 include ground-glass opacities (GGO) and consolidation with or without vascular enlargement, interlobular septal thickening, and air bronchogram [13]. Other, less common findings include the "reverse halo" sign and pulmonary nodules with a halo sign [13]. Lesions are located predominantly in the peripheral and subpleural and are most commonly found multilocally rather than unilocally [13]. The Radiological Society of North America (RSNA) released a consensus statement that classifies CT features of COVID-19 patients into four categories: Typical, atypical, indeterminate, and negative for pneumonia [16]. In a study conducted by Fang et al., 72\% of COVID-19 patients had typical CT findings, with the remaining $28 \%$ showing atypical CT manifestations [12], [17]. The British Society of Thoracic Imaging (BSTI) further classifies chest CT scans of COVID-19 based on severity: Mild (up to three focal abnormalities, maximum $3 \mathrm{~cm}$ in diameter) and moderate/severe (more than 3 abnormalities or larger than $3 \mathrm{~cm}$ in diameter), where the differentiation between moderate and severe is assessed clinically [18].

Considering the high sensitivity of chest CT and its ability to achieve a prompt diagnosis, combined with the fact that RT-PCR has a relatively low sensitivity and is rather time-consuming, it is, therefore, argued that chest CT plays a critical role along with RT-PCR in diagnosing COVID-19, especially in epidemic areas where rapid and accurate identification of COVID19 patients is needed [15], [19]. However, studies supporting chest CT use as a primary tool to screen, identify, and diagnose COVID-19 are still lacking in Indonesia. We aim to investigate the diagnostic value of chest CT in correlation to RT-PCR in Indonesia.

\section{Materials and Methods}

A cross-sectional study was done where the data were obtained from medical records. This study includes patients who tested positive for RT-PCR and included patients referred to our hospital for RT-PCR testing due to positive rapid tests results in which the results of RT-PCR were negative. Still, the CT scan results initially showed lesions suggestive of COVID-19. Patients with positive testing were then traced back for chest CT scan data and other descriptive data such as age, sex, comorbidities, and presence of symptoms, and whether they were admitted to the intensive care unit (ICU). Flowchart of the inclusion criteria is shown in Figure 1.

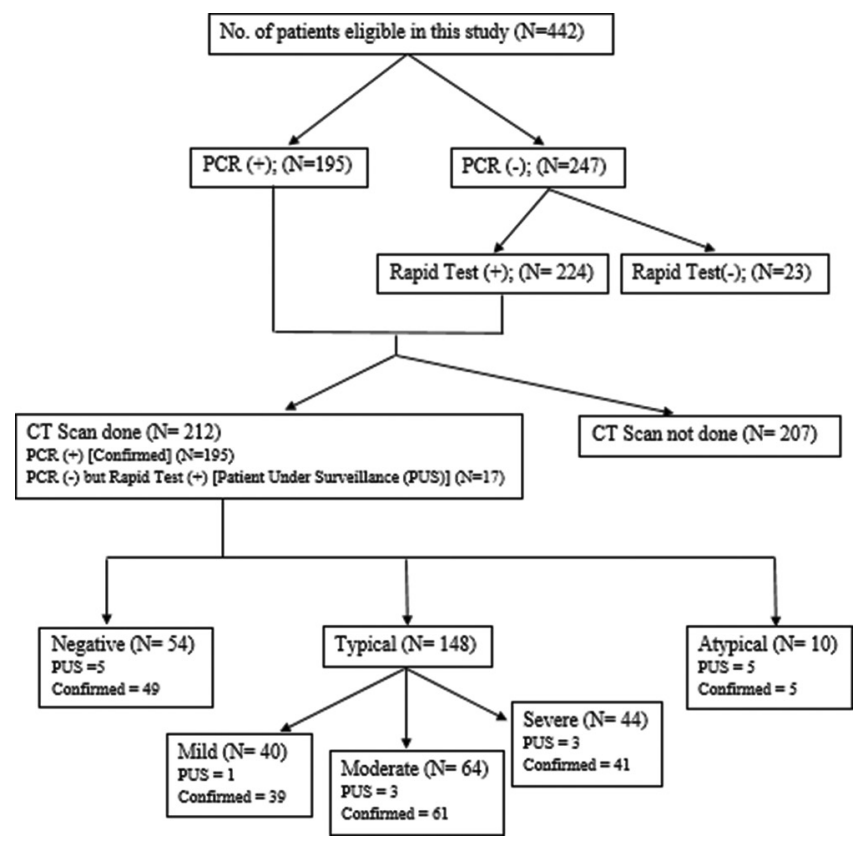

Figure 1: Flowchart of the study

Patients who were positive for COVID-19 were defined as patients who tested positive SARS-CoV-2 by RT-PCR from March 2020 to June 2020 in Siloam Hospitals Lippo Village. The classification of COVID-19 diagnosis referred to the $4^{\text {th }}$ edition guidelines that were released by Minister of Health of Indonesia on March 27, 2020 [20]. Conversion of PCR was defined as the number of days taken from the first positive RT-PCR results to two consecutive negative results of RT-PCR and conversion was only measured in those who tested positive for RT-PCR. Traveling was defined as any visits outside the countries or nation from December 2019 up to RT-PCR testing while contact with COVID-19 patients was defined as any gatherings or close contacts with patients known positive for COVID-19. The number of days taken from the onset of symptoms to CT scan was defined as the $1^{\text {st }}$ day of onset of COVID-19 manifested by signs and symptoms suggestive of COVID-19. If the patients were asymptomatic, this value would be 0 days. Geriatric was defined as age $\geq 65$ years old.

Two expert radiologists interpreted the CT scan results and classification of the $\mathrm{CT}$ scan was according to the RSNA classification [16]. Severity of the CT scan referred to BSTI consensus [18]. Any conflicts in interpretation were resolved internally according to the consensus. Both radiologists were consultants in thoracic imaging, and they were both blinded for the diagnosis and test results of RT-PCR. Signs and 
symptoms were revealed to allow interpretation of radiological findings according to clinical symptoms. Chest CT scan was done in Siemens SOMATOM Drive Straton MX Sigma (Siemens AG, Germany). Simultaneously, the RT-PCR samples were obtained through nasopharyngeal swab and analyzed with QIAGEN Rotor-Gene Q (Roche Molecular Systems, USA).

The primary objective was to analyze whether the CT scan was sensitive and specific enough to detect lesions of COVID-19. Other analyses were done to analyze whether the CT scan will detect typical lesions in symptomatic and asymptomatic patients and look at the severity of CT scan and their association with admission to the ICU. Descriptive statistics were used for representing the demographic and clinical variables. Association between variables is assessed with $\chi^{2}$. Statistical analysis was performed using SPSS Version 23 (Statistical Package for the Social Sciences, IBM Corp., Armonk, NY, USA).

The committee approved this study protocol on Ethics at University of Pelita Harapan, Tangerang, Indonesia, with approval number of 153/K-LKJ/ETIK/ VIII/2020 with protocol number 01082020.

\section{Results}

A summary of descriptive data on the correspondents studied is shown in Table 1. A total of 212 correspondents' data were collected where $92 \%$ of them were diagnosed as confirmed cases of COVID19. The high patient number who did not undergo CT scan among negative PCR cases could be explained by the fact that since insurances do not cover CT scan for patients who were not positive by PCR testing even though their rapid testing is positive, most patients were reluctant to make out-of-pocket payment for $\mathrm{CT}$ scan. The mean age was 45.5 years old $( \pm 15.2)$, predominant toward males $(54.7 \%)$. In this study, the mean days taken for conversion of RT-PCR were 13.2 days $( \pm 16.7)$. The number of days taken from the onset of symptoms to the CT scan was 4.1 days ( \pm 4.8 days).

Out of all the lesions, GGOs were the most frequent lesion detected $(59.4 \%)$ followed by crazy paving (33\%) and consolidation (22.6\%). In comparison, the parenchymal band $(3.8 \%)$ and halo sign $(0.9 \%)$ were the least detected lesions. Other lesions were found, such as tuberculosis fibrosis, mosaic patterns, subsolid nodules, and acute respiratory distress syndrome, which made up $8.5 \%$ of the lesions.

According to RSNA classification, $69.8 \%$ CT scan findings were typical, $4.7 \%$ were atypical, while $25.5 \%$ was negative for COVID-19. With BRTI consensus, $27 \%$ of the lesions were mild, $43.2 \%$
Table 1: Descriptive analysis of correspondents

\begin{tabular}{|c|c|}
\hline Characteristics & Results \\
\hline Age (years) & $45.5( \pm 15.2)$ \\
\hline \multicolumn{2}{|l|}{ COVID-19 diagnosis classification (\%) } \\
\hline Confirmed & $195(92)$ \\
\hline Patients under surveillance & $17(8)$ \\
\hline \multicolumn{2}{|l|}{$\operatorname{Sex}(\%)$} \\
\hline Male & $116(54.7)$ \\
\hline Female & $96(45.3)$ \\
\hline Conversion of RT-PCR (days) & 13.2 days $( \pm 16.7)$ \\
\hline \multicolumn{2}{|l|}{ Ground-glass opacity (\%) } \\
\hline Yes & $126(59.4)$ \\
\hline No & $86(40.6)$ \\
\hline \multicolumn{2}{|l|}{ Crazy paving (\%) } \\
\hline Yes & $70(33.0)$ \\
\hline No & $142(67.0)$ \\
\hline \multicolumn{2}{|l|}{ Consolidation (\%) } \\
\hline Yes & $48(22.6)$ \\
\hline No & $164(77.4)$ \\
\hline \multicolumn{2}{|l|}{ Curvilinear band (\%) } \\
\hline Yes & $34(16.0)$ \\
\hline No & $178(84.0)$ \\
\hline \multicolumn{2}{|l|}{ Traction bronchiolectasis (\%) } \\
\hline Yes & $25(11.8)$ \\
\hline No & $187(88.2)$ \\
\hline \multicolumn{2}{|l|}{ Atoll sign $(\%)$} \\
\hline Yes & $12(5.7)$ \\
\hline No & $200(94.3)$ \\
\hline \multicolumn{2}{|l|}{ Halo sign (\%) } \\
\hline Yes & $2(0.9)$ \\
\hline No & $210(99.1)$ \\
\hline \multicolumn{2}{|l|}{ Parenchymal band (\%) } \\
\hline Yes & $8(3.8)$ \\
\hline No & $204(96.2)$ \\
\hline \multicolumn{2}{|l|}{ Fibrosis (\%) } \\
\hline Yes & $13(6.1)$ \\
\hline No & $199(93.9)$ \\
\hline \multicolumn{2}{|l|}{ Others (\%) } \\
\hline Yes & $18(8.5)$ \\
\hline No & $194(91.5)$ \\
\hline Classification (\%) & \\
\hline Atypical & $10(4.7)$ \\
\hline Negative & $54(25.5)$ \\
\hline Typical & $148(69.8)$ \\
\hline Grading of CT (\%) & \\
\hline Mild & $40(27.0)$ \\
\hline Moderate & $64(43.2)$ \\
\hline Severe & $44(29.7)$ \\
\hline Outcome (\%) & \\
\hline Alive & $203(95.8)$ \\
\hline Dead & $9(4.2)$ \\
\hline Days from onset of symptoms to CT scan & $4.1( \pm 4.8)$ \\
\hline Traveling (\%) & \\
\hline Yes & $11(5.2)$ \\
\hline No & $201(94.8)$ \\
\hline Contact with positive cases (\%) & \\
\hline Yes & $56(26.4)$ \\
\hline No & $156(73.6)$ \\
\hline Admission into ICU (\%) & \\
\hline Yes & $15(7.1)$ \\
\hline No & $197(92.9)$ \\
\hline Presentation (\%) & \\
\hline Symptomatic & $135(63.7)$ \\
\hline Asymptomatic & $77(36.3)$ \\
\hline Comorbidities & \\
\hline Asthma & 3 \\
\hline Previous tuberculosis & 4 \\
\hline Geriatric & 50 \\
\hline Hypertension & 4 \\
\hline Diabetes mellitus type 2 & 4 \\
\hline Pregnancy & 1 \\
\hline Dyslipidemia & 2 \\
\hline Coronary artery disease & 2 \\
\hline Chronic obstructive pulmonary disease & 1 \\
\hline
\end{tabular}

were moderate, while $29.7 \%$ were severe lesions (Figures 2-4). The outcome found in this study was $95.8 \%$ of patients were alive, while $4.2 \%$ were dead. Meanwhile, $7.1 \%$ of patients were admitted to the ICU (Table 1).

Table 2 describes the association between the usefulness of chest CT scan in detecting lesions in COVID-19 patients. It was found that the sensitivity of CT scan for COVID-19 patients was $72.3 \%$ (65.5\% and 


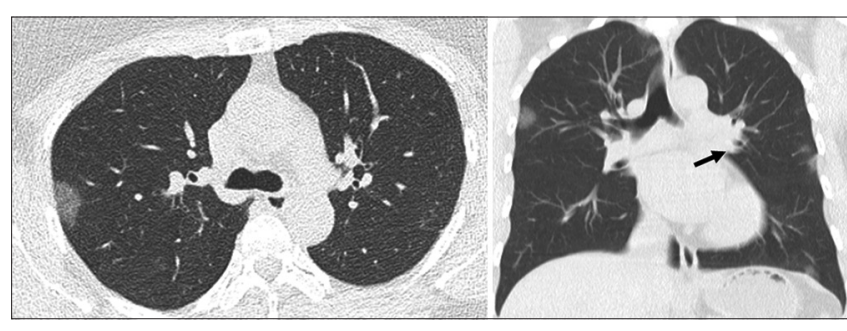

Figure 2: Mild coronavirus disease 2019 chest computed tomography scan axial view (left) and coronal view (right), indicating multifocal ground-glass opacities (black arrows)

$78.5 \%$ ) with positive predictive value (PPV) of $93.9 \%$ $(90.9 \%$ and $96.0 \%)$. However, with $18.8 \%$ (12.0\% and $28.3 \%$ ) negative predictive value (NPV), it means that normal or atypical CT scans could not exclude the diagnosis of COVID-19.

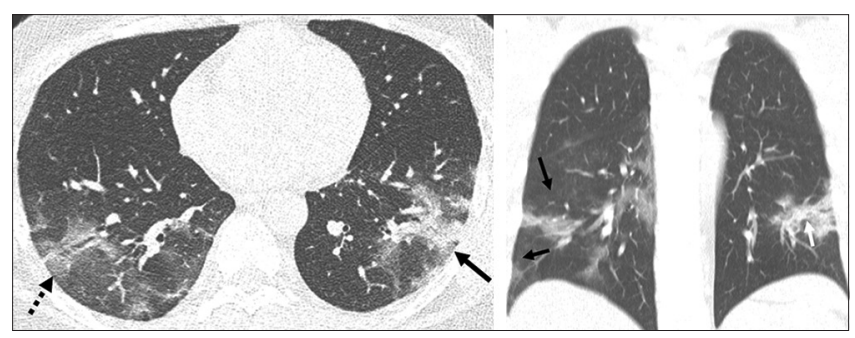

Figure 3: Moderate coronavirus disease 2019 chest computed tomography scan axial view (left) and coronal view (right), indicating multifocal ground-glass opacities (black arrows), crazy paving (dotted black arrow), and atoll sign (white arrow)

Table 3 shows the usefulness of chest CT scan in detecting lesions in symptomatic COVID-19 patients, and it found that the sensitivity was $88.1 \%$ with PPV value of $97.4 \%$. This means that the sensitivity and PPV of the CT scan will increase in symptomatic patients.

Typical chest CT scan lesions were 8.0 times which were more likely $(3.9-16.4 ; p<0.001)$ to be detected in symptomatic patients (Table 4) while patients with severe CT scan findings were 4.4 times more likely $(3.0-6.5 ; p<0.001)$ to be admitted to the ICU (Table 5).

\section{Discussion}

In this study, we found that the mean age was 45.5 years old $( \pm 15.2)$ whereas one study conducted in
Wuhan by Zhou et al. where they found that the mean age was 52.3 years old $( \pm 13.1)$ from a total of 272 CT scans. This might be explained by the fact that patients who came into our clinic were $36.3 \%$ asymptomatic. It was found that people with younger age without any comorbidities tend to be asymptomatic, and hence, these patients might skew the mean age [21]. The mean days taken for conversion of RT-PCR were 13.2 days ( \pm 16.7 days), longer than another study conducted by $\mathrm{Ai}$ et al. where the conversion to after negative was 6.9 days ( \pm 2.3$)$ [15]. In our study, one possibility that could explain the longer conversion time might be because RT-PCR results typically took 1-2 weeks and if the results were positive, the patients needed to wait for another 1-2 weeks until two negative tests were achieved. Comparison of other studies is shown in Table 6.

Wang et al. found that most COVID-19 patients had a patchy or combination of GGO and consolidation opacities similar to our studies [22]. This study also found that CT's time duration in COVID-19 was 1.54 days $( \pm 0.946)$ while our study showed that patients took longer days. While partly it could be explained by the much lower participant number $(n=13)$ in the study done by Wang et al., it could also be explained by the fact that asymptomatic patients are unlikely to be checked with CT scan for COVID-19 due to cost issues and limited availability of CT scan in primary clinics and hospitals. Therefore, patients could undergo a CT scan only after they were referred to our hospital, which prolonged the CT scan time duration [20].

Ai et al. found that CT scan was $97 \%$ sensitive (95\% and 98\%) for confirmed COVID-19 patients with an NPV of $68 \%$ (65\% and $70 \%)$ and accuracy of $68 \%$ $(65 \%$ and $70 \%)$ while we only found that the sensitivity for CT scan was $72.3 \%(65.5 \%$ and $78.5 \%)$ with an NPV of $18.8 \%(12.0 \%$ and $28.3 \%)$ and accuracy of $59.6 \%$ (52.7\% and $66.2 \%)$. Meanwhile, we reported a higher specificity $57.9 \%(33.5 \%$ and $79.8 \%)$ with a higher PPV of $93.9 \%$ (90.9\% and $96.0 \%)$ compared to Ai et al. which reported specificity of $25 \%(22 \%$ and $30 \%)$ with a lower PPV of $65 \%$ (62\% and $68 \%$ ). This might be because our samples were only $1 / 5$ of the study done by $\mathrm{Ai}$ et al. and hence the sensitivity calculation lacks volume. Furthermore, the differences in study design might explain the differences in findings. While our study only included those who tested positive for RT-PCR or positive CT scan findings as inclusion criteria, Ai et al.

Table 2: Usefulness of chest CT scan in detecting lesions in COVID-19 patients

\begin{tabular}{|c|c|c|c|c|c|c|c|}
\hline CT Scan & Confirmed & Patients under surveillance & Sensitivity $(95 \% \mathrm{Cl})$ & Specificity $(95 \% \mathrm{Cl})$ & PPV $(95 \% \mathrm{Cl})$ & NPV $(95 \%$ CI) & Accuracy $(95 \% \mathrm{Cl})$ \\
\hline Typical & 141 & 7 & $72.3(65.5,78.5)$ & $57.9(33.5,79.8)$ & $93.9(90.9,96.0)$ & $18.8(12.0,28.3)$ & $59.6(52.7,66.2)$ \\
\hline Non-typical & 54 & 10 & & & & & \\
\hline
\end{tabular}

Table 3: Usefulness of chest CT scan in detecting lesions in symptomatic COVID-19 patients

\begin{tabular}{|c|c|c|c|c|c|c|c|}
\hline CT scan & Confirmed & Patients under surveillance & Sensitivity $(95 \% \mathrm{Cl})$ & Specificity $(95 \% \mathrm{Cl})$ & PPV $(95 \% \mathrm{Cl})$ & NPV $(95 \% \mathrm{Cl})$ & Accuracy $(95 \% \mathrm{Cl})$ \\
\hline Typical & 104 & 7 & $88.1(80.9,93.4)$ & $58.8(32.9,81.2)$ & $97.4(95.1,98.9)$ & $22.4(14.0,33.8)$ & $62.3(52.6,70.5)$ \\
\hline Non-typical & 14 & 10 & & & & & \\
\hline
\end{tabular}


categorized their participants into four groups which included a combination of positive or negative RT-PCR and positive or negative CT scan [15].

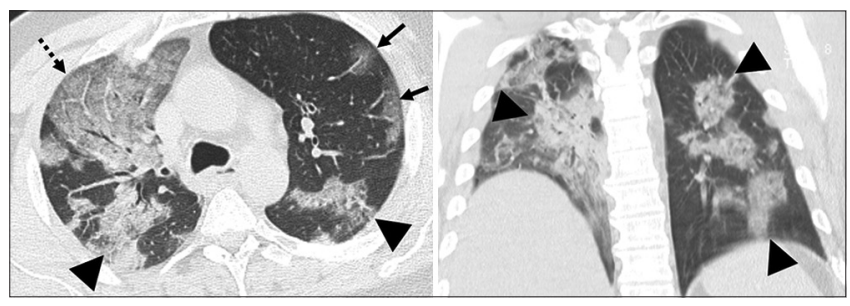

Figure 4: Severe coronavirus disease 2019 chest computed tomography scan axial view (left) and coronal view (right) indicating multifocal ground-glass opacities (black arrows), crazy paving (dotted black arrow), and consolidation (arrowheads)

Chest CT scans in symptomatic patients, however, seem to have a higher sensitivity and PPV. We found that chest CT scans' sensitivity in detecting COVID-19 was $88.1 \%$, with a PPV of $97.4 \%$. In their study of assessing the sensitivity of chest CT scan in patients with epidemiological or clinical features compatible with COVID-19, Fang et al. found that chest CT scans have a sensitivity $98 \%$ [12]. Smet et al. also compared the sensitivity and specificity of chest CT scans between asymptomatic and symptomatic patients. They found that the sensitivity of chest CT scans was $89.1 \%$, while in asymptomatic patients, sensitivity was only $45.0 \%$. They concluded that chest CT scans' sensitivity in asymptomatic patients was insufficient to justify it as a screening tool [23]. Therefore, as Shatri et al. pointed out, CT should not be used to screen asymptomatic patients for COVID-19, but may be considered in symptomatic patients [24].

Based on our data, symptomatic COVID-19 patients were more eight times more likely to have typical $(104 / 118 ; 88 \%)$ than non-typical features $(14 / 118 ; 12 \%)$ in their chest CTs. This contrasts to asymptomatic patients, where typical $(37 / 77 ; 48 \%)$ and non-typical features $(40 / 77 ; 52 \%)$ were almost

Table 4: Usefulness of chest CT scan in detecting lesions in confirmed COVID-19 patients

\begin{tabular}{lllll}
\hline CT scan & Symptomatic & Asymptomatic & OR $(95 \% \mathrm{Cl})$ & p-value \\
\hline Typical & 104 & 37 & $8.0(3.9-16.4)$ & $<0.001$ \\
Non-typical & 14 & 40 & & \\
\hline CT: Computed tomography, COVID-19: Coronavirus disease 2019. & &
\end{tabular}

Table 5: Admission to ICU based on severity of CT scan

\begin{tabular}{lllll}
\hline CT scan & ICU & Non-ICU & OR severe $(95 \% \mathrm{Cl})$ & p-value \\
\hline Mild-moderate & 2 & 103 & $4.4(3.0-6.5)$ & $<0.001$ \\
Severe & 17 & 26 & & \\
\hline CT: Computed tomography, ICU: Intensive care unit.
\end{tabular}

equally likely to be found in their chest CTs. This finding draws similarities to a study conducted on the "Diamond Princess" cruise ship in Japan, which found that $79 \%$ had lung opacities in symptomatic patients. In comparison, in asymptomatic patients, they were present in only 54\%. All asymptomatic patients with lung opacities had GGOs with or without interlobular septal thickening or consolidation. The lung opacities in $90 \%$ of the asymptomatic patients with lung opacities had peripheral or mixed distribution, while the rest had lung opacities of central distribution. In $78 \%$ of the asymptomatic patients with lung, opacities had multifocal lesions, while $22 \%$ had unifocal lesions. In another study of asymptomatic patients conducted by $\mathrm{Hu}$ et al., $50 \%$ of patients had COVID-19 typical features of GGOs, while $20 \%$ had atypical findings, with the rest having normal chest CTs [25]. A study conducted in Wuhan, China, by Meng et al. found that the predominant CT findings in asymptomatic patients were GGOs (94.8\%) that were multifocal $(62.1 \%)$ and peripherally distributed $(75.9 \%)$, but unilaterally located (58.6\%) [26].

Our data show that patients with a severe chest CT scan severity on admission are 4.4 times more likely to be admitted to the ICU than those with only mildmoderate chest CT scan severity. This is in concordance to a study conducted by Chen et al., in which it was found that COVID-19 patients admitted to the ICU had more lobes involved and more widespread distribution of lesions than those who have been discharged [27]. A similar finding was found in a study by Ruch et al., in which patients with over $50 \%$ of lung involvement in their chest CTs were associated with ICU admission and early death [28]. Therefore, initial chest CT may play a prognostic value in COVID-19 patients and help predict their outcome.

Our study has several limitations. First, using RT-PCR assays with a relatively low positive rate as the reference standard, the chest CT scan sensitivity for COVID-19 may be overestimated, and the specificity is underestimated. The second limitation is that due to this study's nature, we could not assess the time taken for patients to undergo CT scan after an initial positive RT-PCR test. Any correlations with clinical and laboratory data could not be obtained due to the hospital's overload. Third, since this is a cross-sectional study using past data, we could not include any control samples. Finally, since our hospital was not the referral

Table 6: Comparison of other studies

\begin{tabular}{|c|c|c|c|c|c|c|c|c|c|}
\hline Author & Title & Year & Country & Sensitivity & Specificity & PPV & NPV & Accuracy & Sample size \\
\hline Ai et al. [15] & $\begin{array}{l}\text { Correlation of chest CT and RT-PCR testing for coronavirus disease } 2019 \\
\text { (COVID-19) in China: A report of } 1014 \text { cases }\end{array}$ & 2020 & China & 97 & 25 & 65 & 83 & 68 & 1014 \\
\hline Falaschi et al. [30] & $\begin{array}{l}\text { Chest CT accuracy in diagnosing COVID-19 during the peak of the Italian } \\
\text { epidemic: A retrospective correlation with RT-PCR testing and analysis of } \\
\text { discordant cases }\end{array}$ & 2020 & Italy & 90.7 & 78.8 & 86.4 & 85.1 & 85.9 & 773 \\
\hline Arslan et al. [31] & $\begin{array}{l}\text { Correlation of chest CT and RT-PCR testing in coronavirus disease } 2019 \\
\text { (COVID-19) in Turkey }\end{array}$ & 2020 & Turkey & 43 & 74 & 96 & 6 & 44 & 610 \\
\hline Caruso et al. [32] & Chest CT features of COVID-19 in Rome, Italy & 2020 & Italy & 97 & 56 & 59 & 96 & 72 & 158 \\
\hline Mirahmadizadeh et al. [33] & $\begin{array}{l}\text { Sensitivity and specificity of chest CT scan based on RT-PCR in COVID-19 } \\
\text { diagnosis }\end{array}$ & 2021 & Iran & 78.6 & 42.3 & 59.5 & 64.7 & 60.2 & 54 \\
\hline
\end{tabular}


hospital for COVID-19, there were few study samples available. However, despite the circumstances, this study provided another perspective from Indonesia in using CT scan as a feasible screening method for COVID-19.

\section{Conclusion}

The chest CT scan has good sensitivity for COVID-19 patients, which improves symptomatic patients. A high PPV suggests that chest CT scan can detect COVID-19 lesion, but the absence of the lesions would not exclude the disease's presence. Future studies should also assess follow-up chest CT scan in COVID-19 patients as it was reported that reactivation of COVID-19 could also contribute to radiological changes in chest CT scan [29].

\section{References}

1. World Health Organization. Pneumonia of Unknown CauseChina. Geneva: World Health Organization; 2020. Available from: https://www.who.int/csr/don/05-january-2020-pneumoniaof-unkown-cause-china/en. [Last accessed on 2020 Jul 29].

2. World Health Organization. Naming the Coronavirus Disease (COVID-19) and the Virus that Causes it. Geneva: World Health Organization; 2020. Available from: https://www.who. int/emergencies/diseases/novel-coronavirus-2019/technicalguidance/naming-the-coronavirus-disease-(covid-2019)-andthe-virus-that-causes-it. [Last accessed on 2020 Jul 29]. https:// doi.org/10.1016/j.wneu.2020.03.068

3. World Health Organization. Mission Summary: WHO Field Visit to Wuhan, China. Geneva: World Health Organization; 2020. Available from: https://www.who.int/china/news/detail/22-012020-field-visit-wuhan-china-jan-2020. [Last accessed on 2020 Jul 29].

4. Karam M, Althuwaikh S, Alazemi M, Abul A, Hayre A, Gavin B. Chest CT versus RT-PCR for the detection of COVID-19: Systematic review and meta-analysis of comparative studies. medRxiv. 2020;2020:6846. https://doi. org/10.1101/2020.06.22.20136846

5. World Health Organization. WHO Director-general's Opening Remarks at the Media Briefing on COVID-19. Geneva: World Health Organization; 2020. Available from: https://www.who.int/ $\mathrm{dg} / \mathrm{speeches/detail/who-director-general-s-opening-remarks-}$ at-the-media-briefing-on-covid-19---11-march-2020. [Last accessed on 2020 Mar 11]. https://doi.org/10.1596/35731

6. World Health Organization. WHO Coronavirus Disease (COVID-19) Dashboard. Geneva: World Health Organization; 2020. Available from: https://www.covid19. who.int/?gclid=Cj0KCQjwvIT5BRCqARIsAAwwD-R2_ g9ENNXUZpwIvd2JE7_68niL 7 I9q7TBMpqmQthBcZmvMI2LbBcaAhlIEALw wcB. [Last accessed on 2020 Jul 27].

7. Vetter $P$, Vu DL, LHuillier AG, Schibler M, Kaiser L, Jacquerioz $F$. Clinical features of covid-19. BMJ. 2020;369:m1470. https://doi. org/10.1136/bmj.m1470
8. Guan W, Ni Z, Hu Y, Liang W, Ou C, He J, et al. Clinical characteristics of coronavirus disease 2019 in China. N Engl J Med. 2020;382(18):1708-20.

9. Wu Z, McGoogan JM. Characteristics of and important lessons from the coronavirus disease 2019 (COVID-19) outbreak in China: Summary of a report of 72314 cases from the Chinese center for disease control and prevention. JAMA. 2020;323(13):1239-42. https://doi.org/10.1001/jama.2020.2648 PMid:32091533

10. Cascella M, Rajnik M, Cuomo A, Dulebohn S, Di Napoli R Features, Evaluation and Treatment Coronavirus (COVID-19). StatPearls Publishing; 2020. Available from: https://www. ncbi.nlm.nih.gov/books/NBK554776. [Last accessed on 2020 Jun 28].

11. Yang $Y$, Yang $M$, Shen $C$, Wang $F$, Yuan J, Li J, et al. Evaluating the accuracy of different respiratory specimens in the laboratory diagnosis and monitoring the viral shedding of 2019-nCoV infections. MedRxiv. 2020. https://doi. org/10.1101/2020.02.11.20021493

12. Fang $\mathrm{Y}$, Zhang $\mathrm{H}$, Xie J, Lin $M$, Ying L, Pang $P$, et al. Sensitivity of chest CT for COVID-19: Comparison to RT-PCR. Radiology. 2020;296(2):E115-7. https://doi.org/10.1148/radiol.2020200432 PMid:32073353

13. Li Y, Xia L. Coronavirus disease 2019 (COVID-19): Role of chest CT in diagnosis and management. AJR Am J Roentgenol 2020;214(6):1280-6. https://doi.org/10.1016/j.ijsu.2020.05.018 PMid:32130038

14. Abbasi-Oshaghi E, Mirzaei F, Farahani F, Khodadadi I, Tayebinia $\mathrm{H}$. Diagnosis and treatment of coronavirus disease 2019 (COVID-19): Laboratory, PCR, and chest CT imaging findings. Int J Surg. 2020;79:143-53. PMid:32422384

15. Ai T, Yang Z, Hou H, Zhan C, Chen C, Lv W, et al. Correlation of chest CT and RT-PCR testing in coronavirus disease 2019 (COVID-19) in China: A report of 1014 cases. Radiology. 2020;296(2):E32-40. https://doi.org/10.1148/radiol.2020200642 PMid:32101510

16. Simpson S, Kay FU, Abbara S, Bhalla S, Chung JH, Chung M, et al. Radiological society of North America expert consensus statement on reporting chest CT findings related to COVID-19. Radiology. 2020;2(2):e200152. https://doi.org/10.1148/ ryct.2020200152

17. Waller J V, Kaur P, Tucker A, Lin KK, Diaz MJ, Henry TS, et al. Diagnostic tools for coronavirus disease (COVID-19): Comparing $\mathrm{CT}$ and RT-PCR viral nucleic acid testing. Am J Roentgenol. 2020;215(4):834-8. https://doi.org/10.2214/ajr.20.23418 PMid:32412790

18. Hare SS, Rodrigues JC, Nair A, Jacob J, Upile S, Johnstone A, et al. The continuing evolution of COVID-19 imaging pathways in the UK: A British society of thoracic imaging expert reference group update. Clin Radiol. 2020;75(6):399-404. https://doi. org/10.1016/j.crad.2020.04.002 PMid:32321645

19. He JL, Luo L, Luo ZD, Lyu JX, Ng MY, Shen XP, et al. Diagnostic performance between $C T$ and initial real-time RT-PCR for clinically suspected 2019 coronavirus disease (COVID-19) patients outside Wuhan, China. Respir Med. 2020;168:105980. https://doi.org/10.1016/j.rmed.2020.105980 PMid:32364959

20. Kementerian Kesehatan Republik Indonesia. Pedoman Pencegahan dan Pengendalian COVID-19. Jakarta: Kementerian Kesehatan Republik Indonesia; 2020. https://doi. org/10.31002/rep.v5i1.2050

21. Zhou S, Zhu T, Wang Y, Xia L. Imaging features and evolution on CT in 100 COVID-19 pneumonia patients in Wuhan, China. 
Eur Radiol. 2020;30(10):5446-54. https://doi.org/10.1007/ s00330-020-06879-6

PMid:32367418

22. Wang H, Wei R, Rao G, Zhu J, Song B. Characteristic CT findings distinguishing 2019 novel coronavirus disease (COVID-19) from influenza pneumonia. Eur Radiol. 2020;30(9):4910-7. https:// doi.org/10.1007/s00330-020-06880-z PMid:32323011

23. Smet K, Smet D, Demedts I, Bouckaert B, Ryckaert T, Laridon E, et al. Diagnostic power of chest CT for COVID19: To screen or not to screen. BMJ. 2020. https://doi. org/10.1101/2020.05.18.20097444

24. Shatri J, Tafilaj L, Turkaj A, Dedushi K, Shatri M, Bexheti S, et al. The role of chest computed tomography in asymptomatic patients of positive coronavirus disease 2019: A case and literature review. J Clin Imaging Sci. 2020;10:35. https://doi. org/10.25259/jcis_58_2020 PMid:32547838

25. Hu Z, Song $C, X u C$, Jin $G$, Chen $Y, X u X$, et al. Clinical characteristics of 24 asymptomatic infections with COVID19 screened among close contacts in Nanjing, China. Sci China Life Sci. 2020;63(5):706-11. https://doi.org/10.1007/ s11427-020-1661-4 PMid:32146694

26. Meng $\mathrm{H}$, Xiong $\mathrm{R}$, He R, Lin $\mathrm{W}$, Hao $\mathrm{B}$, Zhang $\mathrm{L}$, et al. $\mathrm{CT}$ imaging and clinical course of asymptomatic cases with COVID-19 pneumonia at admission in Wuhan, China. J Infect. 2020;81(1):e33-9. https://doi.org/10.1016/j.jinf.2020.04.004 PMid:32294504

27. Chen HJ, Quu J, Wu B, Huang T, Gao Y, Wang ZP, et al. Early chest CT features of patients with 2019 novel coronavirus (COVID-19) pneumonia: Relationship to diagnosis and prognosis. Eur Radiol. 2020;30(11):6178-85. https://doi. org/10.1007/s00330-020-06978-4
PMid:32518987

28. Ruch $Y$, Kaeuffer $C$, Ohana M, Labani A, Fabacher T, Bilbault $P$, et al. CT lung lesions as predictors of early death or ICU admission in COVID-19 patients. Clin Microbiol Infect. 2020;26(10):1417. e5-8. https://doi.org/10.1016/j.cmi.2020.07.030 PMid:32717417

29. Chae KJ, Jin GY, Lee CS, Lee HB, Lee JH, Kwon KS. Positive conversion of COVID-19 after two consecutive negative RT-PCR results: A role of low-dose CT. Eur J Radiol. 2020;129:109122. https://doi.org/10.1016/j.ejrad.2020.109122

\section{PMid:32540583}

30. Falaschi Z, Danna PS, Arioli R, Pasché A, Zagaria D, Percivale I, et al. Chest CT accuracy in diagnosing COVID-19 during the peak of the Italian epidemic: A retrospective correlation with RT-PCR testing and analysis of discordant cases. Eur J Radiol. 2021;130:109192. https://doi.org/10.1016/j.ejrad.2020.109192

\section{PMid:32738464}

31. Arslan S, Delice O, Kahraman M, YIImaz SI, Aslan MH. Correlation of chest CT and RT-PCR testing in coronavirus disease 2019 (COVID-19) in Turkey. Ann Clin Anal Med. 2021;12(5):483-7. https://doi.org/10.4328/acam.20310

32. Caruso D, Zerunian M, Polici M, Pucciarelli F, Polidori T, Rucci C, et al. Chest CT features of COVID-19 in Rome, Italy. Pubs RSNA. 2021;296(2):1237. https://doi.org/10.1148/ radiol.2020201237

33. Mirahmadizadeh A, Pourmontaseri Z, Afrashteh S, Hosseinzadeh M, Karimi J, Sharafi M. Sensitivity and specificity of chest CT scan based on RT-PCR in COVID-19 diagnosis. Polish J Radiol. 2021;86(1):74-7. https://doi.org/10.5114/pjr.2021.103858 PMid:33708275 